\title{
CONSERVACIÓN DE FOTOGRAFÍAS ANALÓGICAS Y DIGITALES. EXPERIENCIA EN LA REVISTA BOHEMIA
}

Javier Santovenia Díaz: Instituto Politécnico de Informática Fernando Aguado y Rico de La Habana. Cuba.

interactivo@infomed.sld.cu

Marianela Muñoz Espinosa: Universidad de La Habana. Cuba. nelaespinosa@gmail.com

\section{RESUMEN}

La proyección y visión dada a la conservación de los materiales fotográficos se acrecienta en el contexto de las redes sociales y académicas, pues indudablemente forman parte de la historia, cultura y desarrollo científico de las naciones. El patrimonio fotográfico da fe como testimonio y memoria para aquellos corresponsales, lectores y aficionados habituales de los productos informativos de los órganos de prensa que buscan mostrar la realidad actual que representan. Para ello se valen del dominio de las técnicas de procesamiento de imágenes para que estos productos posean mayor valor agregado y calidad. La Facultad de Comunicación (FCOM) de la Universidad de la Habana tiene el reto de crear y actualizar plataformas infocomunicacionales que sustenten los procesos de transmisión de la información y que respondan a las necesidades comunicativas de sus miembros. Sin embargo, en ella se evidencia como el uso alternativo de las formas analógico-digital de soporte fotográfico es relativamente reciente por parte de los nuevos profesionales que se forman. Cuestión que demuestra la necesidad e importancia de su utilización y conservación en los procesos editoriales-periodísticos con fines comunicativos desarrollados. Se hace una caracterización de los archivos fotográficos de la revista Bohemia como ejemplo de buenas prácticas en la conservación de estos recursos. Se exponen además experiencias sobre la digitalización de imágenes analógicas y el acceso a recursos locales y remotos de los materiales fotográficos.

PALABRAS CLAVE: Fotografía analógica - Fotografía digital - Conservación Universidad de la Habana - Revista Bohemia - Digitalización

\footnotetext{
${ }^{1}$ Autor correspondiente:

Javier Santovenia Díaz: Instituto Politécnico de Informática Fernando Aguado y Rico de La Habana. Cuba.

Correo: interactivo@infomed.sld.cu
} 


\title{
CONSERVATION OF ANALOGUE AND DIGITAL PHOTOGRAPHS. EXPERIENCE IN THE MAGAZINE BOHEMIA
}

\begin{abstract}
The projection and vision given to the conservation of the photographic materials increase in the context of the social and academic nets, because undoubtedly they form part of the history, culture and scientific development of the nations. The photographic patrimony gives faith like testimony and memory for those correspondents, readers and habitual fans of the informative products of the press organs that they look for to show the current reality that you/they represent. For they are been worth it of the domain of the techniques of prosecution of images, so that these products possess bigger added value and quality. The Ability of Communication (FCOM) of the University of the Havana (UH) he/she has the challenge of to create and to upgrade info-communicational platforms that sustain the processes of transmission of the information and that they respond to the talkative necessities of their members. However in her it is evidenced as the alternative use in the analogicaldigital ways of photographic support it is relatively recent on the part of the new professionals that are formed. Question that demonstrates the necessity and importance of their use and conservation in the editorial-journalistic processes with developed talkative ends. After a brief journey on the emergence and development of the analogical picture in Cuba, direct antecedent of the digital one that coexists next to her in all the production contexts and digitalization. A characterization of the photographic files of the magazine is made Bohemia like example of good practical in the conservation of these vital resources for the educational and educational ends of the FCOM. It is also exposed experiences on the digitalization of analogical images and the access to local and remote resources of the photographic materials.
\end{abstract}

KEY WORDS: Analogical photography - Digital photography - Conservation University of La Habana - Magazine Bohemia - Digitize

\section{INTRODUCCIÓN}

La Facultad de Comunicación de la Universidad de la Habana (FCOM) es una organización con fines docentes-educativos donde el intercambio e interacción entre cada uno de sus miembros ha jugado un papel decisivo en el funcionamiento y desarrollo de los procesos educativos y de socialización. Todos los estudiantes de pregrado y posgrado consideran que el material fotográfico es una fuente de información y parte insustituible del patrimonio visual y documental, que posee diferentes aplicaciones dentro sus currículos de especialidades; pero que en todos los casos constituye un eslabón con el pasado y un impresionante registro de él. De ahí la importancia de su conservación para poder gestionar su localización y recuperación en el momento indicado. 
El egresado de la FCOM reconoce cuales requisitos deben establecerse para lograr una crítica fotográfica favorable y sobre todo consistente con los factores de tipo técnico, de composición y emocionales, que sistemáticamente rigen elementos como el encuadre, la compensación, el enfoque, el balance de blancos, hasta aquellos que se refieren al propósito, las emociones y el interés. El blog de fotografía DZoom ahonda en cada uno de ellos.

La ciencia de la conservación reconoce y analiza la estructura de los diferentes procesos fotográficos, los factores de deterioro y las medidas para prevenirlos. Puesto que las instantáneas son objetos frágiles y vulnerables que se componen de diversos estratos de materia de origen orgánico e inorgánico, los cuales se modifican e interactúan repercutiendo en la estabilidad del material. Pero como las innovaciones en el campo de las tecnologías de la información traen consigno la integración de los métodos tradicionales con los modernos, debido a los disímiles intereses bajo el propósito de elaborar productos comunicativos para las diferentes audiencias. La conservación fotográfica ha extendido su campo de acción a los formatos digitales.

Vale recordar que la empresa Kodak encargó a Steve Sasson la construcción de la primera cámara digital el 12 diciembre de 1975. Ésta necesitaba 23 segundos para guardar una fotografía en blanco y negro en una cinta de casete y otros tantos en recuperarla. Pero es en 1990 cuando comienza la digitalización en el ámbito fotográfico, ya en 1994 Apple presentó la primera cámara digital para consumidores.

La cámara digital es un hibrido entre una cámara analógica y un ordenador, mientras más aumenta sus funcionalidades, más desarrolla las posibilidades en la captura y el tratamiento de imágenes. Ahora se inscriptan por un sensor electrónico y se archivan en un dispositivo denominado memoria, que permite el registro tanto de lo observado directamente, como de lo que sucede brevemente, y que no es perceptible.

Pero todavía existe divergencia de criterios acerca de la calidad de la fotografía analógica y digital. Esta última es criticada por los mitos y temores de los que se niegan a abandonar aquello que les resulta más conocido y comprobado. Sus defensores alegan que producto del desconocimiento es el hecho de pensar que la fotografía digital es de menor calidad que la fotografía analógica, puesto que ahora de manera simple y rápida es posible lograr, y mucho más, todo lo que antes se podía hacer en un laboratorio con químicos, y el procesado y tratamiento se hace más factible, pues se cuenta con la virtud y capacidad de herramientas que dejan definitivamente a la fotografía analógica en un lugar mucho más limitado.

\section{UN BREVE Y NECESARIO RECORRIDO POR LOS ANTECEDENTES DE LA FOTOGRAFÍA ANALÓGICA EN CUBA}

La fotografía hace su aparición en Cuba con una mínima diferencia de solo ochenta y un días a partir de su descubrimiento, presentado ante la Academia de Sciencies el 7 de junio de 1839, por el astrofísico francés Francoise Arango, reconociendo la 
paternidad a su compatriota Louis Jacques Mande Daguerre.

En marzo de 1840, Pedro Téllez-Girón, hijo del capitán general de la isla, realizó el primer daguerrotipo, que mostraba una perspectiva de la Plaza de Armas, La Real Casa de la Administración de Correos e Intendencias y el Castillo de la Fuerza. Esta noticia fue publicada en la primera página del "Diario de la Habana" refiriéndose a ella como un "medio para fijar las imágenes".

Según se plantea en la Enciclopedia Colaborativa Cubana, los primeros fotógrafos en Cuba fueron extranjeros, quienes introdujeron el invento en la isla. Después de TéllezGirón y Halsey, vinieron R. W. Hoit de los Estados Unidos, Antonio Rezzonico, un canadiense de origen italiano, los franceses Marc Vallate, Juan Francisco Delmés, José André y Eugenio Lacroix. De los Estados Unidos también llegaron varios, entre ellos Charles D. Fredricks, que se estableció primeramente en 1857 con Penabert en Obispo $\mathrm{N}^{\circ} 98$.

Se reconoce a Esteban de Arteaga como el primer fotógrafo cubano, especializado en realizar retratos y paisajes, profesor de daguerrotipo e importador de aparatos y reactivos químicos; sin embargo en otras fuentes se afirma que la presencia del primer fotógrafo "natural de la isla" se anuncia el 13 de diciembre de 1844 y no es hasta 1845, en manos de G. Seixas que el daguerrotipo entra en Santiago de Cuba.

Es por esta época cuando en el país comienza a hablarse de colecciones y la fotografía llega a diferentes puertos de la isla, por medio de los comerciantes. Las placas comerciales secas comenzaron a llegar a Cuba hacia 1880 y las primeras preparadas aquí aparecieron hacia 1883, cuando J. S. López abrió una pequeña fábrica en un depósito habanero de efectos fotográficos para el recubrimiento de placas preparadas exclusivamente para los países tropicales, a los cuales registra con la marca comercial Tropical Cubana.

\section{LA CONSERVACIÓN DE LAS FOTOGRAFÍAS ANALÓGICAS Y DIGITALES DE LA REVISTA BOHEMIA}

Para los estudiantes de pre y pos grado de la FCOM la consulta de los archivos fotográficos de la Revista Bohemia constituye una alta prioridad, pues se considera entre las más importantes publicaciones seriadas de su tipo, formadora de la cultura general de varias generaciones de cubanos por su valor testimonial, riqueza temática y el excelente estado de conservación de sus recursos. Además de que Bohemia ha donado parte de sus instalaciones para la nueva construcción de esta institución académica, por tanto sus vínculos se estrechan en pos de desarrollar nuevos ámbitos de colaboración y trabajo profesional.

Fracornel comenta que "Los fondos fotográficos de los órganos de prensa escrita poseen en sus colecciones millares de ejemplares, únicos e irrepetibles que crecen diariamente, como parte de la rutina de producción mediática; y son, además, 
herederos de la fotografía de importantes medios de prensa que existieron en diferentes épocas en el país". (Fracornel, 2000)

El 10 de mayo de 1908 se vendió la primera edición de esta revista, gracias a la buena voluntad de su fundador y propietario Miguel Ángel Quevedo Pérez, también administrador de la Revista El Fígaro. Desde aquel entonces sería un semanario ilustrado, no especializado, que se ocuparía de aquellos asuntos culturales y sociales relevantes para las clases a quienes estaba dirigida. No es hasta enero de 1959, que el quehacer periodístico de la revista incluiría los temas más acuciantes de carácter político del país, y del mundo, junto a los deportivos, culturales, económicos, y científicos respondiendo a la ideología democrática de la naciente Revolución Cubana. En la actualidad la revista consta de 82 páginas en cada quincena, periodicidad de su edición. Para incrementar la visibilidad internacional desde abril del 2002 se incorporó a Internet con una versión digital, que en estos momentos se encuentra en plena fase de trasformación y desarrollo.

Las colecciones fotográficas de la organización tienen una antigüedad de 103 años. La procedencia de ellos es propia del medio al que pertenece. Aproximadamente se cuenta con 1 millón y medio de estos recursos, en soportes como el papel (fotografías sueltas, fotografías montadas en soportes secundarios, albúmenes), soporte digital (fotografías digital, imágenes escaneadas), y soporte plástico (colección de negativos entre ellos lo de Nitrato de Celulosa, y Acetato de Celulosa). Estos se componen de una emulsión sensible, un soporte primario y un aglutinante que adhiere esa emulsión al soporte. En su mayoría presentan además un soporte secundario de cartón duro, y en ocasiones forman parte de su cuerpo otros elementos como adhesivos y tratamientos de superficie.

A partir de la importancia que tiene el recurso fotográfico para la institución unido a que constituye un material permanentemente utilizado por los profesionales del sector periodístico, además de investigadores y otras instituciones. El organismo ha decretado como principal estrategia de conservación que el acceso al material fotográfico se preste en la sala de lectura, donde se facilita únicamente la versión digital, y solo en casos excepcionales, la analógica mientras que se educa correctamente a los usuarios en su manipulación.

El centro estableció una política de conservación preventiva satisfactoria, que reconoce los factores de deterioro, que pueden ser inherentes (técnica de manufactura y materiales constitutivos) o inducidos (factores ambientales, inapropiada manipulación, falta de limpieza, deficiencia en las área de resguardo, ignorancia, negligencia y falta de cuidado). La puesta en práctica de la política ha traído como resultado que se identifiquen pocas fotografías en mal estado, y ante esto, la medida tomada es la digitalización.

La instalación no presenta problemas estructurales pues se encuentra en buen estado. Los archivos fotográficos se localizan en una hemeroteca y fototeca. Donde no existe hacinamiento en el almacenamiento de las colecciones, los negativos de nitrato de 
celulosa se guardan aparte pues algunas veces este material en descomposición es altamente inflamable. En los depósitos no se encuentran otros documentos u objetos ajenos a los materiales fotográficos. Las colecciones se organizan a partir de una previa clasificación que agrupa el material analógico, el plástico en cajas y el digital en una respectiva base de datos. El tratamiento documental incluye campos descriptivos básicos para la representación y la recuperación de la información.

En los depósitos los estantes se encuentran distanciados con un espacio de $1 \mathrm{~m} 2$. Se evita la exposición directa de las fotografías a la luz natural. Se mantienen ubicadas las colecciones de la entidad lejos de las fuentes de humedad (tuberías de agua, paredes externas, filtraciones, entre otras). Los depósitos son lo más herméticos posibles para reducir la existencia de polvo, cambio de color, opacidad, pérdida de resistencia de los materiales. Se prefiere limpiar los pisos de los locales solo con agua antes de recurrir al empleo de solventes, sustancias volátiles o insecticidas. Al proceder a efectuar la limpieza o reparación del material fotográfico se advierte que son extremadamente sensibles a la humedad, a los solventes y a la abrasión, por tanto se siguen los consejos de los especialistas experimentados, en virtud de prevenir daños adicionales.

El organismo cuenta con un plan de reducción de desastres, que declara que los profesionales deben desarrollar competencias y habilidades sistemáticamente en el ámbito de la conservación, y regula que se coloquen extintores portátiles cerca de las salidas de los depósitos y que estén debidamente señalizados.

\subsection{La conservación de fotografías digitales en la Revista Bohemia.}

Es conocida la diferencia en cuanto al origen de creación, entre los tipos de documentos digitales prestos a conservar, presentándose aquellos generados directamente en formato digital y los que se han convertidos de analógicos a digitales en el trascurso del tiempo. Toda medida de conservación gira en torno al mantenimiento de una moderna-consistente infraestructura tecnológica y de un adecuado desempeño profesional que necesita irremediablemente ser sustentado en la capacitación y el conocimiento de todas las técnicas y estrategias de conservación posibles, que garanticen la transmisión de la información y su accesibilidad con el mayor grado posible de autenticidad. Siendo para ello estrategias claves la migración, los reequipamientos, los refrescamientos, la emulación de la tecnología, y el replicado o renovación de los soportes.

La conservación de las fotografías digitales en las instituciones cubanas se enfoca en la dimensión centrada en el proceso de digitalización de los documentos analógicos con un alto grado de deterioro y un marcado carácter patrimonial. Los principales problemas que poseen están determinados por la escasez de recursos financieros, tecnológicos y la poca preparación con que cuentan los recursos humanos. Pocos centros poseen documentos rectores relacionados con la preservación digital, la mayoría ellos se basan en criterios de selección. Por tanto en ocasiones lo digitalizado se conserva en su totalidad, trayendo consigo problemas de almacenamiento y 
pérdidas de información relevante. Sin embargo es evidente como los directivos se sensibilizan ante el problema, y establecen alternativas en base a los recursos financieros disponible en sus organizaciones.

Cuando se realiza el proceso de digitalización de materiales fotográficos en la Revista Bohemia, se almacenan en los soportes ópticos CD y DVD, pues constituyen materiales alternativos por su poco costo y fácil gestión. Una de las medidas de conservación que se desarrolla es la actualización, donde se copian los materiales fotográficos de aquellos soportes que han quedado obsoletos a otros más actuales. También se produce el replicado o renovación de soporte, donde se realiza una copia a los documentos, trasladándola a otro soporte de almacenamiento de forma periódica. Los profesionales se valen de algunos programas recuperadores de archivos borrados que han sido creados bajo la mirada de la disciplina Arqueología digital, la cual "incluye métodos y procedimientos para rescatar contenidos de medios dañados o de entornos de hardware y software obsoletos o dañado" que permiten la recuperación de la información contenida en los soportes dañados u obsoletos. Algunos de estos programas son de Disk Investigator 1.32, Drive Rescue v.1.9, Easy Recovery Profesional, Handy Recovery, Office Recovery Ultimate 1.0. (Univers. Cornell, 2003).

\subsection{La digitalización de imágenes analógicas y el acceso a recursos locales y remotos de imagen fotográfica.}

A partir de una correcta conservación de documentos fotográficos en formato analógico los miembros de la FCOM digitalizan aquellos afines a sus productos informativos, pues consideran que este proceso implica mejorar las funcionalidades de la imagen y su visibilidad. Es por ello que la conversión analógica a digital tiene lugar en un contexto de uso, donde en virtud de las necesidades y actividades se digitalizan aquellas imágenes que facilitaran el procesamiento, codificación, y comprensión de los mensajes.

A continuación se muestran algunas herramientas teniendo en cuenta criterios actuales y evidentes sobre la conservación de las imágenes; los criterios de selección cubren factores de preservación (de reutilización, de patrimonio histórico, etc.) que especialistas como los redactores o editores generalmente en ocasiones no consideran, cuando es importante para la consecución de un buen archivo de imágenes. (Vázquez M. 2006); hay criterios que parten desde un análisis matemático.

A partir de los algoritmos de proyección, estos han evolucionado a partir del algoritmo de proyección alternante propuesto por J. von Neumann en 1933, donde el espacio solución es la intersección de un número finito de subespacios o conjuntos convexos. Según Investigaciones recientes se han centrado en técnicas para acelerar la convergencia del método y explotar el multiprocesamiento. Se conoce también de revisiones cronológica de las diferentes técnicas en las que se ha aplicado el método de las proyecciones ortogonales alternantes al problema de restauración de imágenes, transitando hasta llegar al enfoque reciente de Combettes (1997-1999), en donde la restauración se basa en el cálculo de proyecciones aproximadas, en lugar de 
proyecciones exactas, las fotos de patrimonio histórico y cultural, así como derivadas de profundas investigaciones utilizan estos métodos para su procesado y conservación. (Escalante, 2011)

Las imágenes que utilizan los miembros de la FCOM, se benefician constantemente de estas nuevas versiones del procesamiento de imágenes de conservación, al ser estas más amigables y certeras en sus métodos, al ofrecer soluciones para su mejor conservación.

\subsection{De sus gestores programas.}

Picturesque es una aplicación que permite otorgar efectos externos a las imágenes, para que no queden simples o planas, sin modificarla en sí, sino su apariencia exterior. Proporciona 5 efectos, "la perspectiva" que le otorga más profundidad, "el reflejo" muy de moda en todas las imágenes que suben a la web, se recomienda un reflejo de un $45 \%$ a un 40 de opacidad, "la sombra", también otorga profundidad generando la impresión de que la imagen está en una estantería de cristal. Con el cuarto se da curvatura a las esquinas, y finalmente podemos ponerle un marco o borde del color que deseemos. Esta aplicación permite almacenar la configuración de efectos editados, y su reutilización en las próximas imágenes.

ResizeMe constituye otra opción que permite transformar un grupo de imágenes de forma desatendida, al configurar las acciones que se deseen implementar en el programa, automáticamente se realizan y guardan los cambios de manera rápida y eficiente. Las opciones presentadas son: cambiar el tamaño, rotar, cortar, girar, añadir sombra, cambiar el formato, añadir marcas de agua, y reflejos. El programa soporta los formatos más comunes de imagen e incluso PDF.

Funtastic Photo es perfecto para aplicar efectos a las imágenes, contiene un navegador, donde a partir de criterios predefinidos por los usuarios se selecciona dentro de un universo de imágenes recuperadas, la que se desean modificar. Luego ofrece dos opciones: la básica que consiste en aplicar efectos predefinidos y la avanzada, que crea un efecto propio con los diferentes filtros que incluye. Los efectos básicos comprenden las configuraciones para cámaras antiguas (Vintage) con el cual se puede simular, el sepia de 1880, la cámara de caja de 1900 o el Technicolor de los años 30. También posibilita la rectificación de errores comunes en las imágenes. Los efectos creados bajo la modalidad avanzada permiten intervenir en dos capas la frontal y la posterior. En ellas es posible aplicar efectos de manera independiente y controlar las mezclas. Los efectos individuales tienen controles propios para su ajuste se agrupan en herramientas de reparación (12 efectos), ajustes de color (13 efectos) artísticos (16 efectos) y retoques finales (8 efectos).

Prosterino es una herramienta muy utilizada por aquellos amantes de la fotografía que les gusta hacer regalos, con él se puede crear disímiles poster mosaico, editables según la preferencia de los usuarios. Proporciona 23 plantillas con distribuciones de poster diferentes. Al seleccionar una platilla la muestra con los huecos a rellenar 
posiblemente con fotos archivadas en el disco duro, o de lo contrario se podrá utilizar su navegador que también identifica y localiza imágenes en iPhoto, Aperture, y Lightroom. Prosterino permite crear nuestra propia distribución y salvarla para proceder a la recuperación de la información en próximas ocasiones.

ImageOpthim es la herramienta más simple de todas las presentadas, pues únicamente se utiliza para optimizar el tamaño de las imágenes sin perder calidad aparente. Para ello las somete a 7 filtros, que las comprimen y perfeccionan. Esta aplicación es muy utilizada por los diseñadores, puesto que necesitan hacer funcionar a los servicios web rápidamente cuando se carguen en el navegador, funciona con los formatos JPEG y GIF, PNG.

Deep es una herramienta especializada en filtrar fotos en base al criterio color. Un ejemplo hipotético que refleja su funcionamiento es cuando el usuario ha desarrollado un documento que ya tiene un formato determinado, y precisa de una imagen que quede bien con su proyecto. Es entonces cuando Deep muestra una paleta de colores de las fotos que contiene las colecciones, y al usuario seleccionar uno o varios colores, filtra las fotografías por tal criterio. Pero el no copiará ni duplicará las imágenes, simplemente registrará y guardará un enlace a ellas para su posterior localización. Otros criterios para la identificación y recuperación de imágenes es el tipo de imágenes, por ubicación, por tamaño y por valoración (valor que se puede también dar dentro de Deep). Es decir, su objetivo radica en facilitarte la recuperación de imágenes que mejor se ajusta al documento que se está creando.

Los investigadores consideran a "la conservación del pasado tiene una influencia tanto filosófica como política en a conformación del respeto nacional. Esa noción de autoestima comunitaria esta íntimamente ligada a una memoria colectiva que proyecta y señala las perspectivas de un país" (M Montoya, 2011).

Con relación al estado actual de la fotografía se manifiesta que cesta tendrá "mayor peso en el contenido icónico y simbólico, frente al aspecto material", por estar insertos en una época artística de tendencia conceptual, donde lo histórico y lo didáctico se unen con lo patrimonial. Se sugiere como actuaciones prioritarias a la hora de tazar una pieza fotográfica, realizar una adecuada catalogación, ya que los datos que aporta ofrecerán una correcta valoración económica y patrimonial.

\section{CONCLUSIONES}

Evidencio la investigación realizada en Bohemia, que los materiales fotográficos son de vital importancia para la gestión y tratamiento de la información y constituyen, un material de estudio y consulta, además de apoyar a los productos comunicativos que los estudiantes de pre y posgrado de la FCOM de la Universidad de la Habana tienen que trabajar para sus prácticas de curso.

Los archivos fotográficos de la Revista Bohemia constituyen materiales de alto valor documental y patrimonial pues reflejan el acontecer nacional e internacional; es un 
tesoro patrimonial, constituyendo su banco fotográfico un importante recurso de uso y consulta.

La necesidad de crear y perfeccionar hoy las imágenes digitales es primordial para los que conforman productos comunicacionales, pero nunca deberá ser más importante que preservar para el mañana, aunque en este momento las necesidades e intereses fluctúen. De que vale tener mucho si concientizamos poco, esta es la forma de expresar que mientras más se necesite y se utilice algo más se deberá conservar y tenerlo como antecedente para lo que inevitablemente sucederá.

\section{REFERENCIAS}

Blog de fotografía DZoom. Revisado el 1 de marzo del 2012. Disponible en: www.dzoom.org.

Cabrera, D. \& Reyes, L. (2006). Propuesta de lineamientos para el tratamiento documental de la fotografía de prensa en los medios de prensa cubanos. La Habana.

Csillag, I. (2000). Conservación de Fotografía Patrimonial. Santiago de Chile: Centro Nacional de Conservación y Restauración.

Espinosa, B (2010). Conservación preventiva de los documentos digitales: una visión desde las instituciones cubanas encargadas de conservar el patrimonio documental nacional. Bibliotecología y Ciencia de la Información. Ciudad de La Habana, Universidad de La Habana.

Escalante, R. (2011). “Algoritmos numéricos para el problema de restauración de imágenes usando el Método de las Proyecciones Alternantes". Vol. 11, no. 1. Revista de matemática teoría y aplicación. Disponible en:

http://simmac.emate.ucr.ac.cr/index.php/revista/article/view/288

Fracornel, G. (2000). Manual de diagnóstico de conservación en archivos fotográficos. México: Archivo General de la Nación-Cooperación Iberoamericana.

Gómez, A., Dorta, M. \& Montes de Oca, L. (2009). Métodos diagnósticos del estado de conservación de las colecciones de archivo y biblioteca. Revisado el 1 de marzo de 2012. Disponible en: $\underline{w w w . i h c . n s . c c . c u}$.

Hernández, N. (2000). La conservación de colecciones de negativos de vidrio en instituciones de Ciudad de la Habana: Un estudio de casos. La Habana.

Llevando la teoría a la práctica. Tutorial de digitalización de imágenes (2003). Universidad de Cornell. Consultado e 12 de marzo de 2012. Disponible en:

http:// www.library.cornell.edu/preservation/tutorialspanish/preservation/preservation-03.html 
Fotografía analógica - Fotografía digital - Conservación - Universidad de la Habana Revista Bohemia - Digitalización

León, H. (2001). “Problemática de la conservación preventiva en instituciones cubanas de información". Ciencias de la Información 32 (3).

León, H. (2006). Conservación Preventiva de Documentos. Ciudad de La Habana.

Montoya, M. (2011). “La imagen como memoria. La fotografía como fuente para el estudio de la historia". Revista Actual Investigación. Disponible en: Http://accesoabierto.cecalc.ula

Mustardo, P. (2003). Preservación fotográfica-métodos básicos para salvaguardar sus acervos. Rio de Janeiro: Funarte.

Serra, J. (2001). Gestión de los documentos digitales: estrategias para su conservación. El profesional de la información 10 (9). Revisado el 1 de marzo de 2012. Disponible en: http://www.elprofesionaldelainformacion.com

Vázquez, M. Luisa (2006). El factor humano en un mundo de ficheros. Consultado el 12 de marzo de 2012 Disponible en:

http://srvhost36.serverhosting.apa.net/restricted/madrid_2006/samedi_28/28oct_40 Vazquez_ESP.doc.

\section{Javier Santovenia Díaz}

Máster en Educación y Licenciado en Información Científico-Técnica. Docente en el Instituto Politécnico de Informática Fernando Aguado y Rico de La Habana en Cuba.

\section{Marianela Muñoz Espinosa}

Estudiante de la Facultad de Comunicación en la Especialidad de Ciencias de la Información de la Universidad de la Habana, en Cuba. 